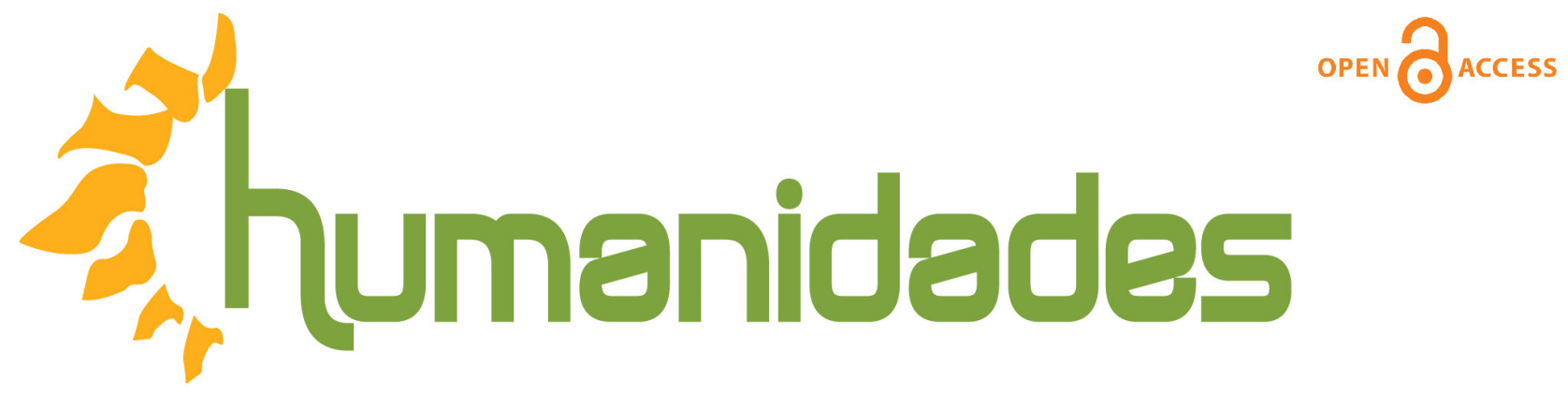

Revista de la Escuela de Estudios Generales, Universidad de Costa Rica

Julio-diciembre, 2019 •Volumen 9, número 2 • EISSN 2215-3934 • pp. 1-27

Recibido: 30-Octubre-2018 Aceptado: 26-Noviembre-2018

\title{
Manifestaciones del pensamiento japonés en la arquitectura de Tadao Ando
}

DOI: https://doi.org/10.15517/h.v9i2.37127

\section{Leticia Oguri Campos}

Máster en representación arquitectónica

Universidad de Ixtlahuaca y el Instituto Tecnológico de Estudios Superiores de Jocotitlán, México

Correo electrónico: ogurile@gmail.com

\section{Linda Emi Oguri Campos}

Doctora

Facultad de Arquitectura y Diseño, Universidad Autónoma del Estado de México, México

Correo electrónico: lindaoguri@gmail.com

Todos los derechos reservados. Universidad de Costa Rica. Esta revista se encuentra licencida con Creative Commons. Reconocimiento-NoComercial-SinObraDerivada 3.0 Costa Rica. Correo electrónico: humanidades@ucr.ac.cr/ Sitio web: http: //revistas.ucr.ac.cr/index.php/humanidades 


\section{Manifestaciones del pensamiento japonés en la arquitectura de Tadao Ando}

\section{Resumen}

La arquitectura de Tadao Ando contiene una intensa expresión de valores a

Palabras clave:

partir de su pensamiento japonés, como la sensibilidad, la reflexión profunda, su espiritualidad y respeto hacia la naturaleza; su discurso va anclado a su origen, combinando la filosofía, las tradiciones y la cultura japonesa. Su arquitectura no permite una sola manera de interpretarse sobre todo porque emplea una gran cantidad de simbolismos y, por tanto, existen diversas perspectivas para su interpretación. En este artículo se muestra la descripción de algunas de sus obras y su relación con conceptos esenciales del pensamiento japonés, de esta manera, la interpretación hermenéutica nos indica que las manifestaciones de elementos sustantivos de su pensamiento son metáforas que nos conducen a la comprensión de nuestra misma condición humana, donde los elementos cotidianos como los materiales, la luz, entre muchos otros, tienen como destino provocar una reflexión profunda; por lo tanto, pueden considerarse como conductos hacia la espiritualidad. No es suficiente tan solo conocer elementos de su procedencia para inferir el sentido de su obra, sino que también resulta importante comprender la visión espiritual de Tadao Ando, quien, al exponer su manera de ser, también nos abre paso para reconfigurar el significado de su arquitectura. 


\title{
Manifestations of the Japanese Thought in the Architecture of Tadao Ando
}

\begin{abstract}
The architecture of Tadao Ando intensely portrays values derived from his Japanese

way of thinking such as sensitivity, deep reflection, spirituality, and respect for

nature; his speech is anchored to his origin, combining Japanese philosophy, traditions, and culture. His architecture does not allow a single interpretation, especially because it employs a large number of symbols and, therefore, there are different perspectives from which it can be analyzed. This article describes some of his works and their relationship with essential concepts of Japanese thought; in this way, the hermeneutic approach indicates that the manifestations of substantive elements of his way of thinking are metaphors that lead us to understand our own human condition, where everyday elements such as materials, light, among many others are destined for inducing a deep reflection; consequently, these elements can be considered an instrument to reach spirituality. Not only is it important to know elements of Tadao Ando's origin to infer the meaning of his work, but it is also fundamental to understand the spirituality of this architect who, by exposing his way of being, enable us to reconfigure the meaning of his work.
\end{abstract}

Keywords: 


\section{La formación de Tadao Ando}

Tadao Ando posee los cuatro premios más prestigiosos de la disciplina: el Pritzker ${ }^{1}$, el Carlsberg ${ }^{2}$, el Praemium Imperiale ${ }^{3}$ y el Premio Kyoto ${ }^{4}$, nacido en la prefectura ${ }^{5}$ de Hanshin en Osaka, Japón, zona que se distingue por su arraigada arquitectura tradicional. Además, sus obras presentan el Kisetsu-kan ${ }^{6}$ (ver figura 1). Todos estos elementos influyeron y enriquecieron de muchas maneras particulares su proceso de diseño y su arquitectura.
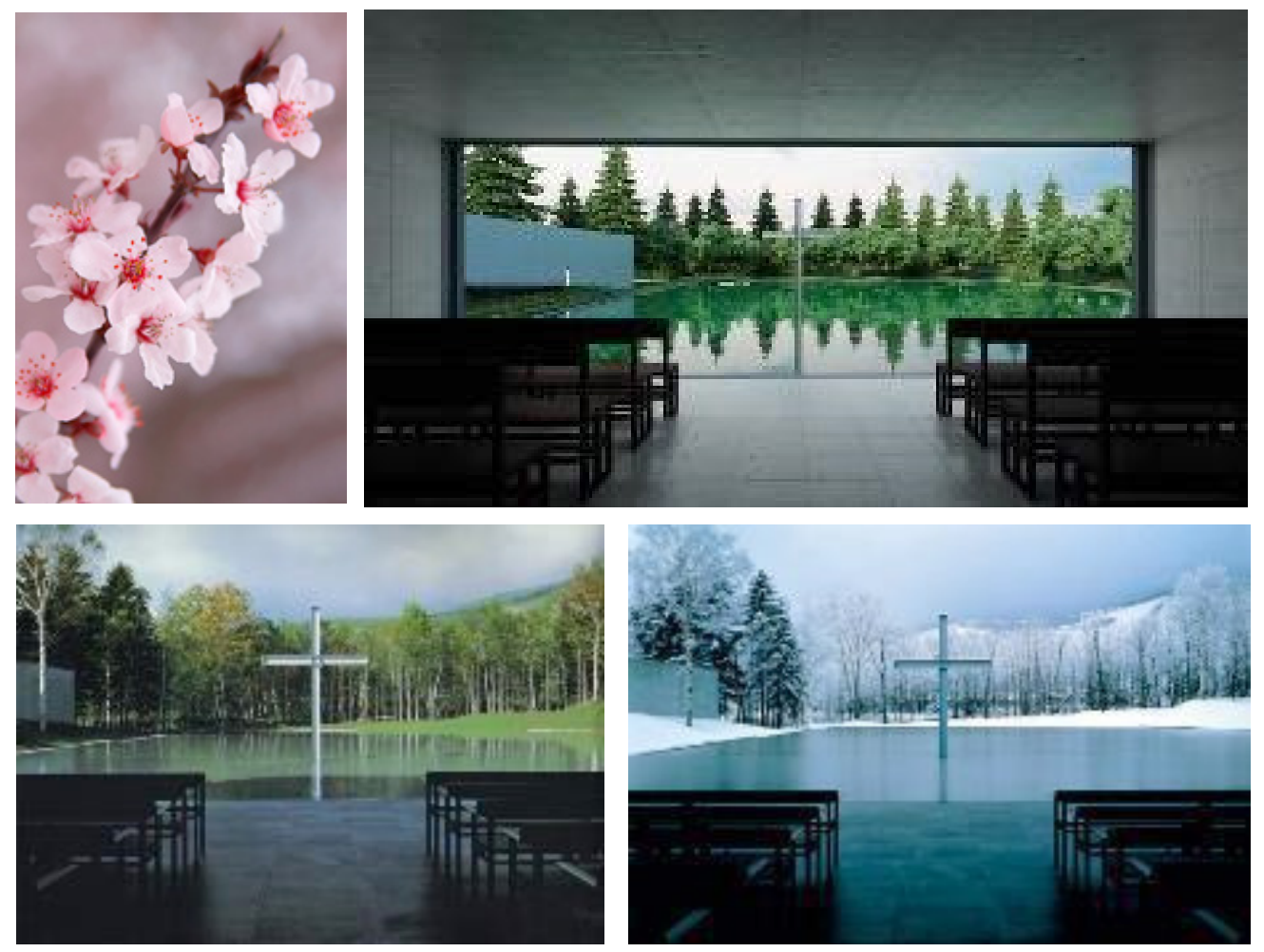

Figura 1. Conjunto de imágenes que muestran el Kisetsu-kan, sentimiento estacional en la obra de Tadao Ando. De izquierda a derecha se presentan: la flor de cerezo de primavera, la vista de la Iglesia del Agua en verano, la Iglesia del Agua en otoño y la Iglesia del Agua en invierno ${ }^{7}$

Tadao Ando es uno de los arquitectos más influyentes en la actualidad. Cabe destacar que su arquitectura no ha sido producto de una educación institucional, puesto que se vio imposibilitado para ingresar a las grandes universidades de arquitectura, así que ser autodidacta fue su camino a seguir. 
Gracias a su capacidad crítica y profunda reflexión ha sabido obtener el conocimiento necesario para ejercer como arquitecto.

Aprendió a colocar su mente y su cuerpo muy cerca de las cosas que dan origen a la vida y a la arquitectura desde muchos puntos de vista abstractos, como el pensamiento, la filosofía, la ética, las tradiciones, así como a través de conocimientos prácticos y concretos. Él narra que el taller de carpintería que se encontraba frente a su casa y el jardín influyeron en su formación durante su infancia; creció haciendo maquetas de madera que aprendió del carpintero y también, al jugar en el jardín, recuerda cómo veía crecer los árboles y cómo percibía la influencia de la luz del sol y la lluvia en el crecimiento de la vegetación. A partir de este contemplar, aprendió la armonía que existe en la naturaleza.

Además de aprender de la práctica, otro aspecto significativo en su proceso de aprendizaje fue el viajar. Ando deseaba ver nuevas cosas y descubrir experiencias examinando en lo profundo. Lo que contempló a través de sus viajes y las visitas a monumentos famosos en el mundo fue realmente fructífero para su arquitectura.

En primer lugar, recorrió Japón, en donde estudió los templos, santuarios y casas de té; observó la arquitectura tradicional referente a los templos shintoistas ${ }^{8}$ que hacen uso de las maderas más ricas del país, principalmente, del ciprés Hinoki que puede dejarse al natural, es decir, sin aditamentos de color en el exterior y pintados de color blanco en su interior como símbolo de la pureza.

En los templos budistas, existen influencias de construcciones de la India, China y Corea, donde se puede observar la inclusión de tonos más vivos, la colocación de estatuas y el uso de accesorios decorativos que no contienen los templos shintoistas. De estas observaciones y reflexiones, Tadao Ando comprende la tradición japonesa, la cual traduce en sus obras con el uso mínimo de recursos y la configuración de espacios puros.

En la arquitectura tradicional japonesa se destaca la utilización de materiales que poseen nobleza, como la madera y el papel. Se dice que son nobles por su capacidad de adaptabilidad tanto a las formas como a otras cuestiones de tipo ambiental y tecnológico. 
Posteriormente, visitó el Partenón en Grecia, el Panteón de Agripa en Roma, el Louvre en París, además de otros trabajos de Palladio, Loos, Aalto, Wright, Mies van de Rohe y le Corbusier y otros sitios famosos (ver figuras 2 y 3 ).

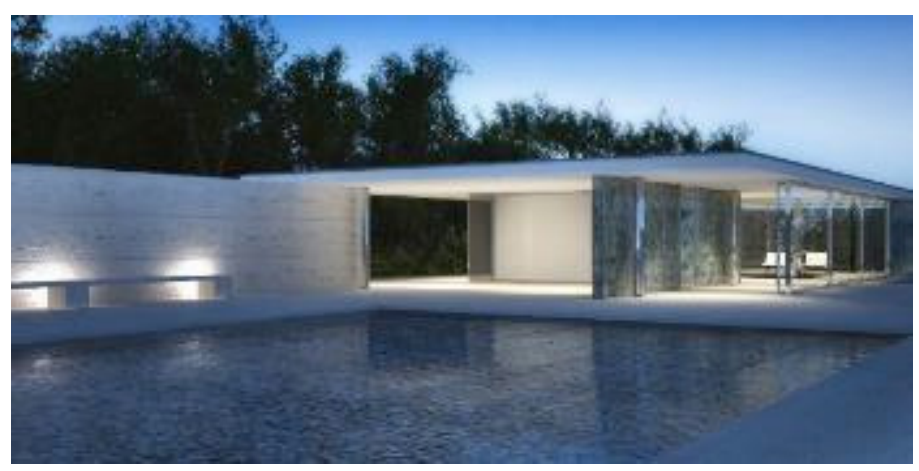

Figura 2. El pabellón Alemán. Diseñado por Mies Van de Rohe y Lilly Reich para la exposición internacional en Barcelona (1929) ${ }^{9}$

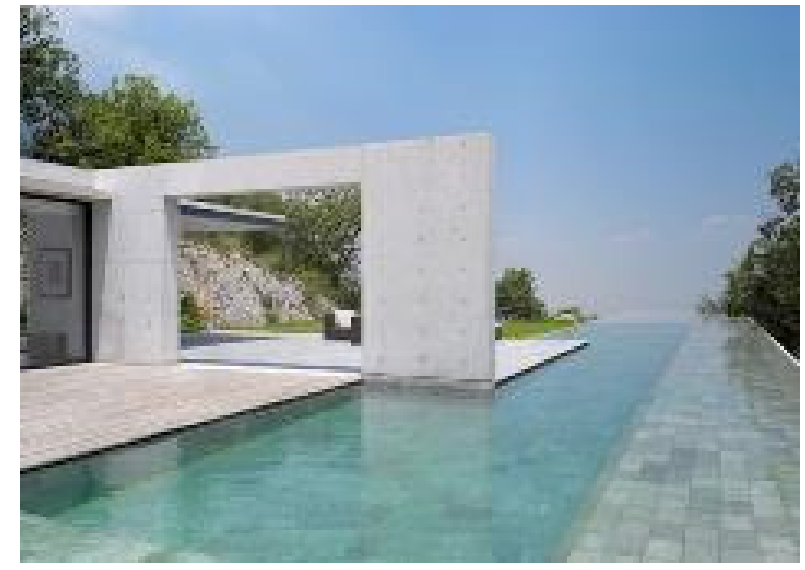

Figura 3. Casa Monterrey, obra de Tadao Ando (2017) ${ }^{10}$

El plasmar en dibujo la arquitectura de distintos lugares es una forma de aprendizaje por medio del descubrimiento en los detalles y la comprensión de la función y la estética, mismos conceptos que se cristalizan a través de su visión subjetiva, humanística y racional y que se reflejan en sus edificios. 
Al explorar numerosos lugares, aprendió a contrastar la arquitectura occidental y oriental. Ejemplo de ello es que, tras su visita a la casa de $\operatorname{Loos}^{11}$ (ver figura 4), descubrió que el espacio puede ser infinitamente diversificado a través de manipulaciones simples y que una forma simple puede enriquecer ampliamente el espacio. Esto lo inspiró mucho, pues menciona que uno de sus conceptos principales es enriquecer la simplicidad (Ando, 1993, p. 18).
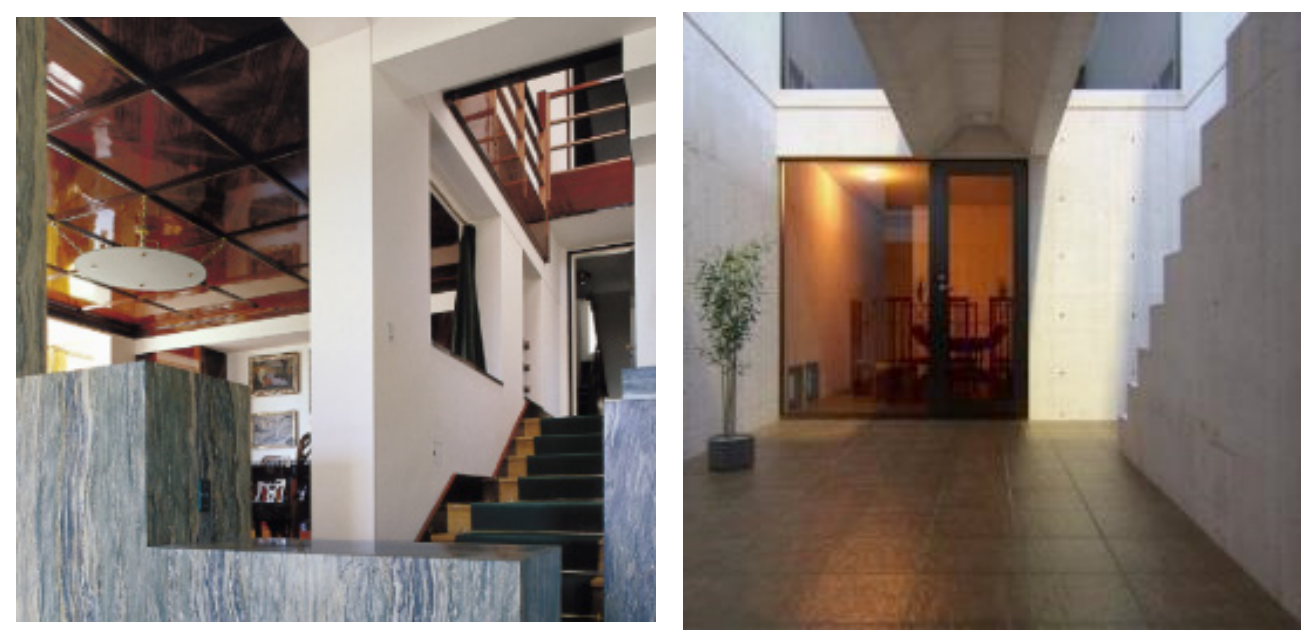

Figura 4. A la izquierda se muestra el interior de la Casa Möller de Adolf. A la derecha el interior de la Casa Azuma de Tadao Ando ${ }^{12}$

Por otra parte, fue influenciado por los arquitectos Louis Kahn ${ }^{13}$ y le Corbusier ${ }^{14}$ respecto a conceptos como la estética abstracta y una concepción modernista de la función material y la forma, donde la abstracción y la geometría son esenciales en el desarrollo de la arquitectura moderna. Tadao Ando conserva la geometría abstracta e incorpora a su arquitectura el sentido de la trascendencia de la tradición japonesa. Además, propone que los principios fundamentales en su arquitectura sean la función clara, la estructura expuesta y la utilización del material crudo, es decir, exhibir la naturaleza propia de cada material. Propone también lo que él llama las relaciones misteriosas entre la arquitectura y la naturaleza, entre la luz y la sombra, que hacen el cambio en el espacio (Pham, 1998, p. 171). 
En otras palabras, su enfoque hacia la arquitectura fue enriquecido por el conocimiento profundo de los materiales, su apreciación del arte, el trabajo de campo y su capacidad de contemplación. Además, es invaluable el papel que ha tomado su educación autodidacta, ya que le ha permitido desarrollar y fortalecer su independencia de pensamiento, donde se destaca tanto su corriente japonesa como su sensibilidad hacia los materiales, la valoración de la belleza natural de las texturas y la comprensión de la impermanencia de la naturaleza y de los seres humanos. Esto le ha permitido realizar sus obras con mayor creatividad visual y una inclinación conceptual más existencial.

Su visión de la sabiduría de pensar y aprender le proporcionó una sensibilidad para el arte y el pensamiento crítico. Él inventó sus principios y teorías de la arquitectura y fundamentó su trabajo en los tres principios de Vitrubio ${ }^{15}$ : utilitas, venustas, firmitas, usándolos en combinación con valores orientales (Pham, 1998, p. 4).

De la arquitectura moderna, él conserva la geometría abstracta. La otra parte viene de la tradición japonesa, de la cual él aprende el medio de la trascendencia. Como resultado, propuso los siguientes principios: una función clara, que contenga materiales utilizados y expuestos en su forma natural (crudo) y estructura expuesta (Ando, 1993, p. 4).

Esta arquitectura es vista desde la dimensión realista y parece carecer de imaginación ficticia. Sin embargo, como Vitrubio enfatizó, venustas (belleza) es una belleza como necesidad junto con la estructura y la función. Ando considera que la dimensión ficticia, combinada con la dimensión realista, crearía la necesidad de sintetizar el efecto profundo en la espiritualidad humana.

Para construir esta arquitectura, Ando ha reunido la razón y la intuición para buscar un espacio que sea un descubrimiento distinto, un entorno que se adapte a la noción del tiempo como producción de una nueva época y a la especificidad del pensamiento, donde se incorpore la ilusión y la realidad en la creación del espacio. 


\section{El pensamiento japonés}

El pensamiento japonés se basa en una relación inseparable entre religión y filosofía que se vive a través de la tradición, las costumbres y las convenciones que son reconocibles y reconocidas en el entramado social. Esta constituye una de las características del pueblo japonés que radica en su capacidad de asimilación adoptando cuanto le interesa, pero imprimiendo siempre el sello de su origen.

Uno de los pilares del pensamiento japonés es, sin duda, el shintoismo ${ }^{16}$, la cual ha sido considerada como la religión más antigua y autóctona de Japón. Ellos expresan que nació al mismo tiempo que su raza misma, por ello, se considera inseparable. Sin embargo, como religión o sistema de pensamiento, nació después de la introducción del budismo. Con el tiempo, se sumaron los conceptos del taoísmo, el confucianismo y del propio budismo; todas estas corrientes no llegaron a destruir la estructura fundamental del shintoismo, sino que se incorporaron, se adaptaron y se transformaron, conteniendo el pensamiento naturalista que se basa en la vida concreta y real, más que en reflexiones metafísicas. No tiene un mesías en sí ni un fundador. Aunque no existen escrituras sagradas como tal, cuenta con narraciones míticas en las que se explica el origen del mundo y de la humanidad. No exige una unicidad de la fe y, sobre todo, otorga la apertura a la adoración cuando se sienta necesidad de ello.

El mundo en el shintoismo es la gran naturaleza, un mundo en el que existe una fuerza vital llamada $M u s u b i^{17}$ que continuamente se está manifestando. Así, los seres humanos y toda la naturaleza son expresiones o manifestaciones del principio inmanente de vida creativa: Musubi.

En el shintoismo la palabra Kami se suele traducir como Dios, sin embargo, significa literalmente 'cabeza', es decir, que se trata del pináculo de la jerarquía, porque en la cultura japonesa no suele existir una separación radical entre lo humano y lo divino, por así nombrarlo, por lo cual se profesa que cualquier japonés se convierte en Kami después de la muerte. 
Para esclarecer la traducción del término Kami, que normalmente se toma como Dios, hacemos referencia a Nishitani ${ }^{18}$ cuando realiza la distinción eckhartiana entre Dios (Gott) y deidad (Gottheit), donde la deidad es la esencia de Dios, Dios en sí mismo desnudado de todos sus atributos como la bondad, la justicia, el amor, etc.

Para el shintoismo, lo que es visible y se manifiesta es menos importante que lo invisible y lo oculto. El término Kami se refiere a la fuerza inmanente de la vida, que es excepcional y superior, que estimula en nosotros un sentimiento de admiración y posee una especie de potencia increíble, algunos otros lo definen como seres espirituales. Hay diversas interpretaciones de los Kami, lo que resulta en propuestas de clasificaciones; algunos los dividen en Kami terrestres y Kami celestes, otros Kami de la tierra y Kami del universo, pero en lo que coinciden es que, como todo es Kami, existen Kami inferiores o malvados. De esta manera, se puede observar la aceptación tanto de lo bueno como de lo malo.

Kami en realidad no se refiere a Dios o Dioses, sino a un conjunto innumerable de fenómenos, por lo que se trata de un mundo de la inmanencia más que de la trascendencia. De esta manera, el centro de gravedad está precisamente en este mundo y no en las alturas, basándose en los procesos naturales del mundo; desde esta visión se dice que todo y todos son Kami, que se posee un potencial Kami (Boyd, 2005, p. 33).

En el shintoismo podemos encontrar creencias básicas que se denominan las cuatro afirmaciones: preservar la tradición y la familia; la naturaleza es sagrada, por lo tanto, debe ser amada, ya que es amar a los Kami, porque la naturaleza es la manifestación física del poder divino; existe aquí un enorme interés por la limpieza física, por cuestiones de purificación y por preservar el honor dado a los Kami ancestrales. El shintoismo mantiene una postura ante la vida de respeto y gratitud. Los practicantes aprecian la belleza y el poder de la naturaleza, elementos que se reflejan en las obras de Tadao Ando. 
Otro principal pensamiento que logra enraizarse en Japón es el budismo, en el cual los japoneses encontraron una respuesta a su naturaleza estética y de donde viene la incorporación de conceptos como karma y dharma, entendidos como soluciones prácticas frente a la insatisfacción vital.

El pensamiento budista consiste en el hallazgo del origen de nuestra propia naturaleza anterior a la consciencia pensante, trata de una búsqueda más intuitiva que lógica, más emocional y física que intelectual. Consideran el dharma como el cosmos, la naturaleza en sus manifestaciones, equilibrada y armónica, donde no hay partes, sino solamente un todo.

El budismo se centra más en la conciencia de la propia debilidad humana que en fuerzas externas, es decir, en lugar de poner más atención al mundo exterior, la atención se enfoca en la interioridad del ser humano, pero sin olvidar que el hombre junto con el mundo natural conforman el gran cosmos. El budismo enseña que la fuerza proviene del mismo ser humano, por lo que resulta necesario que este se domine y se niegue a sí mismo.

El budismo zen hace en repetidas ocasiones alusión a la luna y al agua para ofrecer de alguna manera alguna explicación, donde la reflexión de la luna en el agua es comparable a la experiencia humana, la cual está determinada por la naturaleza de la mente, los sentidos y los objetos, cuya presencia revela la mente. La luna puede ser sinónimo de la sabiduría o de la naturaleza de Buda, en las metáforas que usualmente utiliza el budismo. Además, las artes llamadas japonesas tiene una raíz común que se encuentra en el budismo, que presupone una actitud espiritual, la cual en su forma más elevada corresponde a la forma "no pensar", donde no se pretende ser especulativo, sino vivenciar directamente el mundo, y las artes conforman un pretexto para recorrer el mundo.

Otro elemento importante del pensamiento budista es su concepción de Sunyata, que representa el vacío que lo llena todo (Bukkyo Dendo Kyokai, 1984, p. 143). Es decir, se trata de conseguir la no dualidad, libre de las cosas contrapuestas, puesto que los dos deben existir. El Sunyata, o vacío o la nada, no resulta sinónimo de ausencia; no significa silenciar los sentimientos y tomar una posición indiferente ante la vida, sino poseer una visión universal. 
La vacuidad del budismo es el centro de creatividad, sin confundirlo con el concepto de creación, ya que en el budismo no hay nacimiento ni muerte, por lo que este vacío propone el vivir como estar dispuestos, es decir, estar vacíos para recibir la vida.

Tanto en el shintoismo como en el budismo, lo que importa es seguir el camino respetando todas las cosas. En ambos pensamientos, no existe realmente lo malo o lo bueno como absolutos, puesto que para que uno exista debe manifestarse o compararse con lo otro. Asimismo, el shintoismo es considerado como la adoración a la naturaleza, y el budismo enaltece la relación con ella sobre todas las cosas. El vacío en el shintoismo y el budismo significa que las cosas son como ellas son, en el vacío se tiene la posibilidad de ser, que no representa la inexistencia, sino un lugar donde es posible la plenitud.

\section{Elementos del pensamiento japonés en la arquitectura de Tadao Ando}

Existen elementos del pensamiento japonés que se manifiestan en la arquitectura de Tadao. Como ejemplo encontramos el óvalo en la Casa Museo Benesse, construida en Naoshima, Japón, entre los años 1988 y 1991. El hotel Oval pertenece a uno de los edificios que conforman el complejo de la Casa Benesse, emplazada en la colina sur de la isla de Naoshima, al que se puede llegar desde el Museo Benesse en monorraíl, lo que posibilita observar durante su trayecto todo el conjunto por estar construido en gran parte de manera subterránea, diseño pensado para minimizar el impacto visual sobre la naturaleza circundante. Esta obra consta de un elemento principal cuadrangular donde se encuentra circunscrita la elipse que conforma las habitaciones Por el lado interior del óvalo, se encuentra un gran óculo con un gran cuerpo de agua que evoca a los oráculos griegos, donde las personas pueden explorar el arte, la naturaleza, la arquitectura y sus propios pensamientos de una manera sinérgica y de múltiples capas como lo menciona Ando (Molinari, 2003). El exterior del óculo, con grandes ventanales, armoniza con la naturaleza. 
Manifestaciones del pensamiento japonés...

Respecto a este gran óculo ${ }^{19}$ como el Panteón de $\operatorname{Agripa}^{20}$ (ver figura 5), el arquitecto Ando indica lo siguiente:

Coloqué una caja de hormigón dentro de una madriguera de hurones. La caja tiene un techo suavemente curvado, una de sus paredes se alinea con el eje principal y se inclina hacia la viga de la cresta para generar una sensación de apertura que se extiende dinámicamente hacia el espacio superior. La luz del sol desciende a través del espacio profundo desde el óculo que se abre en la parte superior del techo, su objetivo era crear un espacio que evoque una rica sensación de profundidad a pesar de su pequeño tamaño, donde los elementos de oposición como el pasado y el presente, la madera y el hormigón, y la luz y la sombra chocan intensamente cuando se superponen unos a otros. (Frampton, 1995, p. 2)
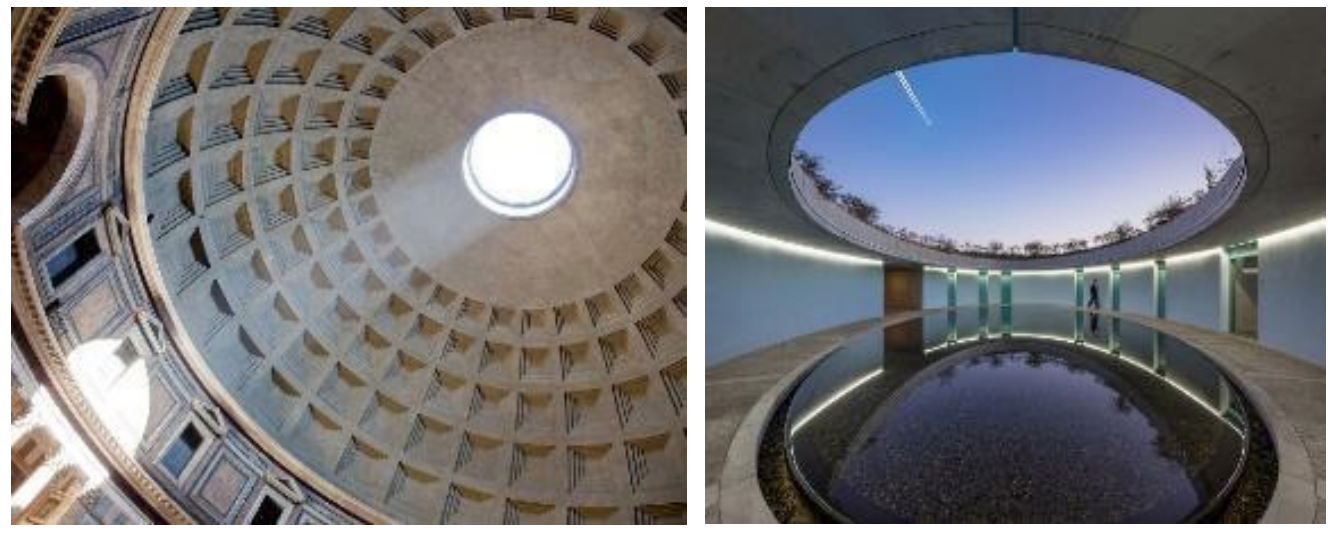

Figura 5. A la izquierda se presenta el Óculo del Panteón de Agripa (118 y 125 d. C.) construido en Roma, Italia. A la derecha se encuentra la obra de Tadao Ando: óvalo de la Casa Museo Benesse (1992) en Naoshima, Japón ${ }^{21}$

Sin embargo, más allá de esta explicación que hace el propio arquitecto, este óculo es un espacio donde puede observarse el exterior, lo que hace referencia a la contemplación de la naturaleza, es decir, la divinidad o Kami según el shintoismo. De acuerdo con Yamamoto Guji ${ }^{22}$, la manifestación del Kami existe en ocasiones o situaciones en nuestras vidas, cuando sentimos sublimidad en un momento, en un lugar, con una persona. 
Puede ser un encuentro con una flor, la belleza de las montañas, la nieve pura, las lluvias o la suave brisa lo que suscita en nosotros admiración y asombro (Havens, 1998). Asimismo, este espacio en su obra, que permite la contemplación del mundo exterior, alude a la enseñanza budista, como el poema haiku de Ryoukan Taigu, quien escribe:

\section{ぬす人に取り殘されし空の月}

\section{Nusubito $n i$}

\section{Torinokosareshi}

\section{Mado no tsuki}

Al ladrón,

Se le olvidó

La luna en la ventana

(Watts, 2003, p. 311)

En este poema la luna representa la enseñanza de Buda que aparece todas las noches, invariable, que existe como tal y no es algo nuevo o viejo, es atemporal. En el budismo, mirar la luna es meditar, y en la obra de Tadao Ando, constituye el óculo que permite la contemplación del cielo, representa la puerta a la meditación y la posibilidad de encontrar la sabiduría.

Es conseguir trascender la mente discriminadora, es decir, ir más allá de ese estado de consciencia en que oponemos unas cosas con otras, ya que no hay armonía cuando se desprende del dualismo, por lo que propone una unificación de conceptos, ideas, valores, entre otros. Se dice que algo es bueno porque existe lo malo, se dice que algo es blanco porque existe el negro, se alumbra porque hay oscuridad y si no existiera la oscuridad no habría alumbramiento.

La obra de Tadao Ando se enfoca en sus propias definiciones y conceptos de la arquitectura, donde destaca su preocupación acerca de la potencialidad y la responsabilidad de la misma disciplina, lo cual apunta a varias hipótesis, una de ellas, consistiría en la filosofía budista y shintoista como base de su pensamiento, así como la valoración de los patrones regionales y su sensibilidad poética que considera las habilidades artísticas del artesano como condiciones necesarias para la creación de una arquitectura que dignifica al ser humano. 
En su iglesia de la luz (ver figura 6), el tema predominante es el vacío porque, en ambas secciones del edificio, el vacío se expresa como el objetivo principal. La caja de luz es un área rodeada por vidrio, donde se establecen las cuatro cruces separadas y el elemento dominante es el cielo azul enmarcado, luz natural que impresiona al espectador con el ideal solemne y transparente.

La vacuidad en el pensamiento japonés, desde la perspectiva filosófica, en especial de los filósofos de la Escuela de Kyoto, lo consideran como el campo de la unidad de cuerpo y mente, de lo subjetivo y lo objetivo. El efecto del espacio vacío que se contempla en su obra, a través de la disposición de los muros y el techo y la cruz calada en la pared, representa, como el budismo indica, un conocimiento que se capta intuitivamente desde la experiencia del propio ser, que propone la liberación de la distinción subjetiva entre el yo y la propia experiencia, con ello se comprueba que la idea de sí mismo no es el sí mismo en realidad, por lo cual se descubre la relación real que existe entre el sí mismo y el mundo exterior.

Por otro lado, la capilla, la segunda área principal, está determinada por el tema de la naturaleza: la tierra horizontal representada con el estanque se extiende silenciosamente ante sus ojos. Tierra y cielo están unidos a través de una línea única; la cruz simbólica (Pham, 1998, p. 8).

La luz es usada como el medio para introducir la vida (habitabilidad) y el alma dentro de un edificio: sus cambios sutiles apoyan la complejidad del espacio. El uso de la luz cenital, el contraste de luz, las sombras interiores y la luz en movimiento en las paredes de concreto crudo o luz reflejada compuesta son elementos clave para alcanzar un alto nivel artístico. 

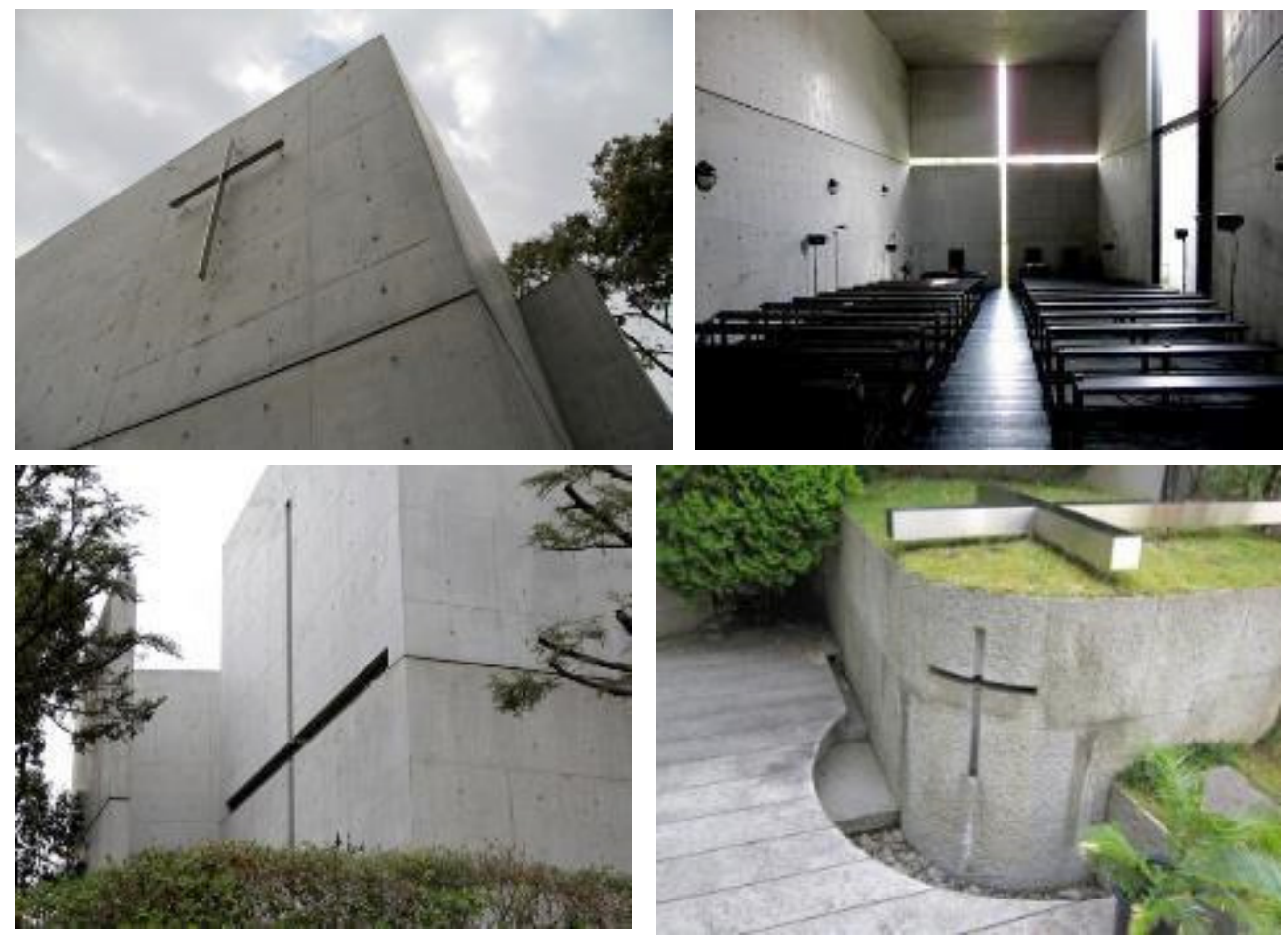

Figura 6. Conjunto de vistas del exterior e interior de la Iglesia de la Luz, Hokkaido, Japón, obra de Tadao Ando ${ }^{23}$

En su iglesia en el agua, construida en Tomamu, en la isla de Hokkaido al norte de Japón, que pertenece al hotel Alpha Resort, Ando utiliza la naturaleza como un elemento sustancial en su diseño; es una iglesia cristiana que contiene elementos del pensamiento budista (ver figura 7).

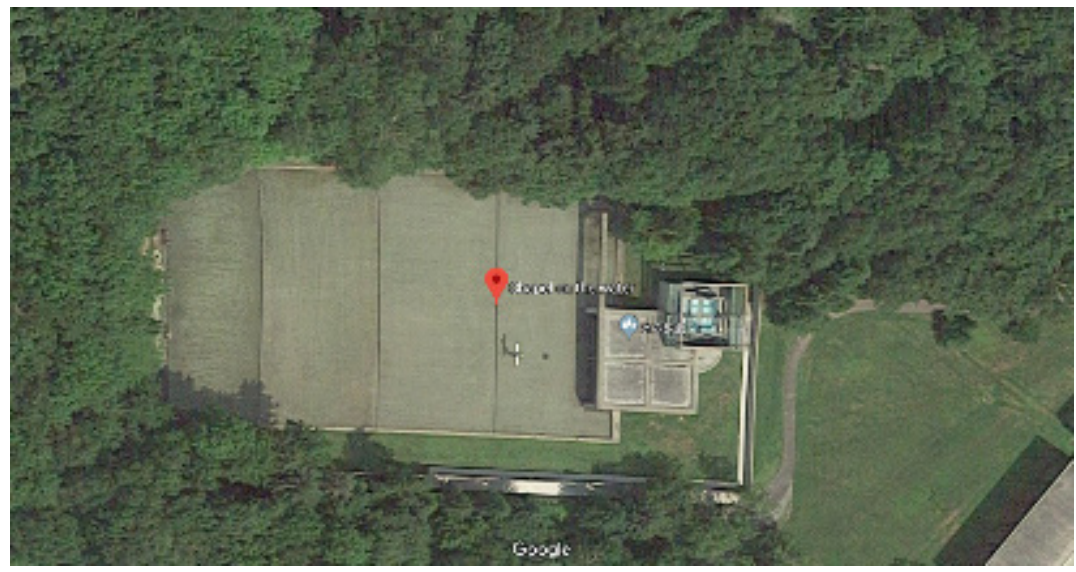

Figura 7. Vista aérea de la iglesia del agua, obra de Tadao $\mathrm{Ando}^{24}$ 
La iglesia se sitúa en la parte posterior del complejo hotelero, a unos 80 metros. La separa un gran muro en "L" hacia el sur y el este, donde hace esa ruptura de lo profano y lo sagrado; se establece ese recinto sagrado aislado de lo terrenal, cuya nave principal, formada por un gran cubo de concreto y vidrio, tiene como remate visual el gran cuerpo de agua formado por cuatro secciones con pequeños desniveles que forman cortas caídas de agua, y el bosque a su entorno. Se intersecta con un segundo volumen en la esquina noreste formado por cuatro cruces, lo que define un cubo virtual. El acceso al recinto se realiza rodeando el gran muro en "L" para descubrir la iglesia desde el lado norte, y unas escalinatas rodean el cubo virtual. Este cubo está cubierto por un techo de vidrio, una estructura de metal y láminas de cristal donde penetra la luz solar tamizada a través del vidrio, dando ese contraste de solemnidad al espacio. De este espacio parte una escalera, oscura y curvada, donde nos encontramos con una quinta cruz emplazada en ese gran lago artificial rodeado por la naturaleza como escenario vivo y multifacético, de acuerdo a las estaciones del año, por lo que se puede interpretar que las cuatro cruces simbolizan los cuatro evangelistas o cuatro evangelios que son los pilares de la iglesia y esa quinta cruz es Jesucristo.

Por otra parte, el gran cuerpo de agua que contiene la obra hace alusión a lo que, en el Shobogenzo, Dogen menciona que el buda Shakyamuni dijo:

The true Dharma Body of the Buddha

Is unbounded like empty space.

It reveals Its form by conforming to an object,

Like water reflecting the moon (Dogen, 2009, p. 571)

La realidad última es descrita como "la luna en el agua", es decir, estar dentro de la realidad, puesto que la enseñanza de Buda es como el espacio, ilimitado, que contiene todos los pensamientos, todas las cosas.

El Satori, o iluminación, es como la luna reflejada en el agua, que se encuentra hasta en cada gota del rocío. La metáfora de la luna reflejada en el agua alude a la forma de aprender de uno mismo, que significa olvidarse de sí, por lo que es iluminado por todas las cosas, lo cual significa dejar caer el cuerpo y la mente. Dogen indica que "estar iluminado es ser uno con todas las cosas" (como se citó en Surya, 2008, p. 31). 
El Satori se puede concebir como la intuición que capta simultáneamente la totalidad e individualidad de todas las cosas. Desde el punto de vista lógico, es percepción de la síntesis de afirmación y negación. En términos psicológicos, es encontrarse más allá de los límites del yo, y en la metafísica, es la aprehensión intuitiva de que ser es devenir y devenir es ser. En el arte budista o arte zen, los artistas, cuando realizan sus obras, se dice que están en un estado de iluminación o Satori, en el sentido de encontrarse íntimamente con ellos mismos y con la naturaleza que tienen ante sus propios ojos.

La iglesia del agua de planta cuadrangular es una de las obras más emblemáticas de Ando. La iglesia carece de ábside, lugar donde se situaría la cruz. Sin embargo, la sitúa en el espacio exterior, por lo que el espacio del altar se funda de forma imaginaria entre la cruz y las bancas, donde el altar es el agua misma que vincula a la naturaleza con lo sagrado, $y$, al igual que la representación simbólica en el budismo, la cruz que representa toda la fe cristiana o a Cristo mismo, en la obra de Ando se representa la cruz como la flor de loto del budismo, donde la flor misma crece en lugares pantanosos, en el fango y, a pesar de ello, su flor se alza sobre la superficie para florecer elevada, fragante, estilizada de impecable belleza, al igual que la religión cristiana. Tanto la cruz como la flor de loto simbolizan la pureza del corazón que surge de entre la inmundicia, lo que recuerda la condición del hombre: hecho de material que se puede corromper, su ser puede elevarse hacia planos sublimes (ver figura 8).
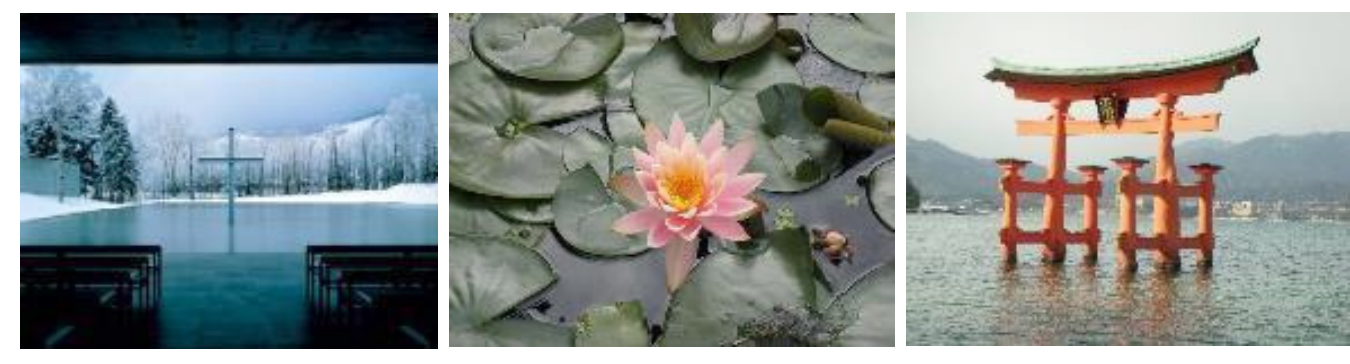

Figura 8. De izquierda a derecha, se presenta lo siguiente: vista del interior al exterior de la Iglesia del agua, obra arquitectónica de Tadao Ando; flor de loto sobre el agua y vista del Santuario de Itsukushima, Miyayima, Japón (foto propia) ${ }^{25}$ 
Encontramos otra similitud en el Templo del Agua que se ubica en la isla de Awaji, en la prefectura de Hyogo, en el mar de Seto, entre las islas de Honshu y Shikoku, en un paraje natural. Esencialmente, el proyecto consiste en un cuerpo elíptico de concreto crudo donde el santuario se encuentra sumergido bajo esta poza elíptica de agua con flores de loto atravesada por una gran escalinata que nos lleva al interior del santuario y nos evoca esa sensación de la penumbra a la luz.

Estos muros tienen dos lecturas: en su exterior, comunicar a la naturaleza de una nueva presencia, y en su interior, generar la sensación de aislamiento y resguardo, como lo podemos encontrar en casi todos los templos tradicionales japoneses donde limitan el espacio con grandes muros cuasi murallas (ver figura 9).
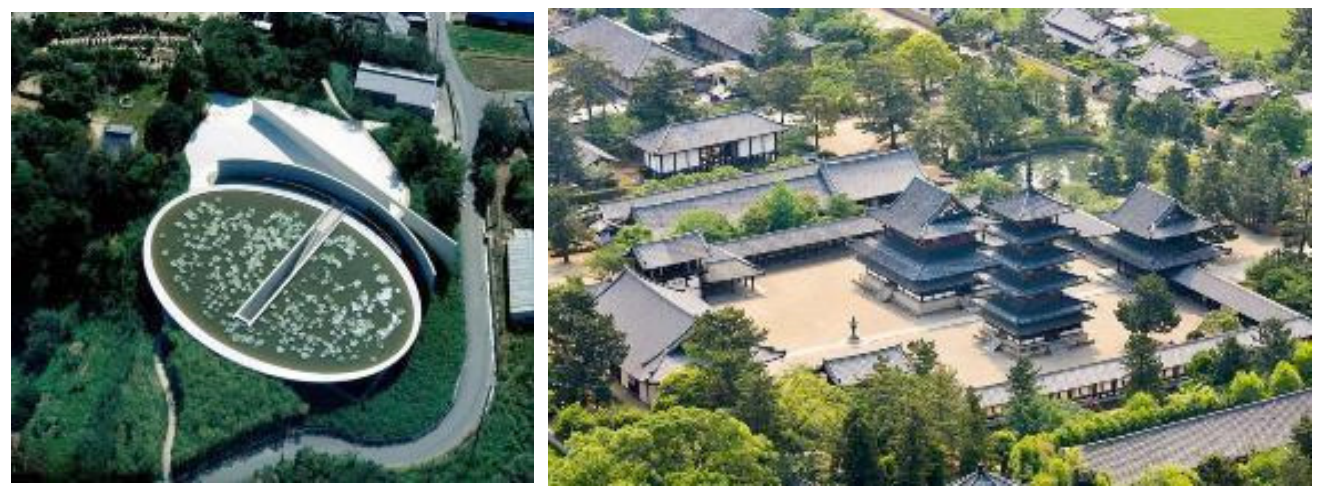

Figura 9. A la izquierda, se presenta una vista aérea del Templo del agua en Hyogo, Japón, obra arquitectónica de Tadao Ando. A la derecha, se aprecia el Complejo Horyuji en Kioto, Japón ${ }^{26}$

Estos muros son objetos que nos interrogan cuando los miramos. Vemos que tienen un espacio delante y otro detrás, que relacionan los espacios, que uno se convierte en interior y otro exterior, lo cual nos cuestiona su relación o nos hace pensar en ella (ver figura 10).
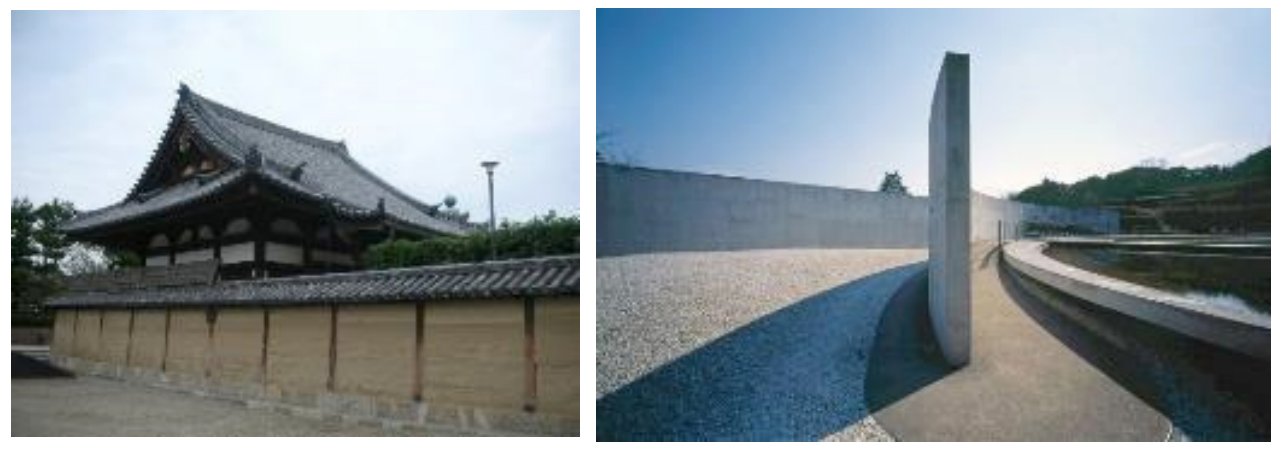

Figura 10. La imagen de la izquierda presenta los grandes muros del Templo del agua, en la isla de Awaji, en la prefectura de Hyogo, Japón. ${ }^{26}$ Por otro lado, la imagen de la derecha muestra una vista del acceso amurallado al complejo Horyu ji, Kioto, Japón ${ }^{27}$ 
En este templo, Ando maneja estos muros como si en esa transición de lo profano a lo sagrado nos estuviese preparando para ese proceso de purificación. Al ir caminando por este pasillo de pequeña gravilla, que antiguamente también servía como delimitación del espacio sagrado, en los templos de la arquitectura tradicional japonesa, los sonidos de las mismas gravillas nos hacen entrar en esa atmósfera mística de gran espiritualidad (ver figura 11).
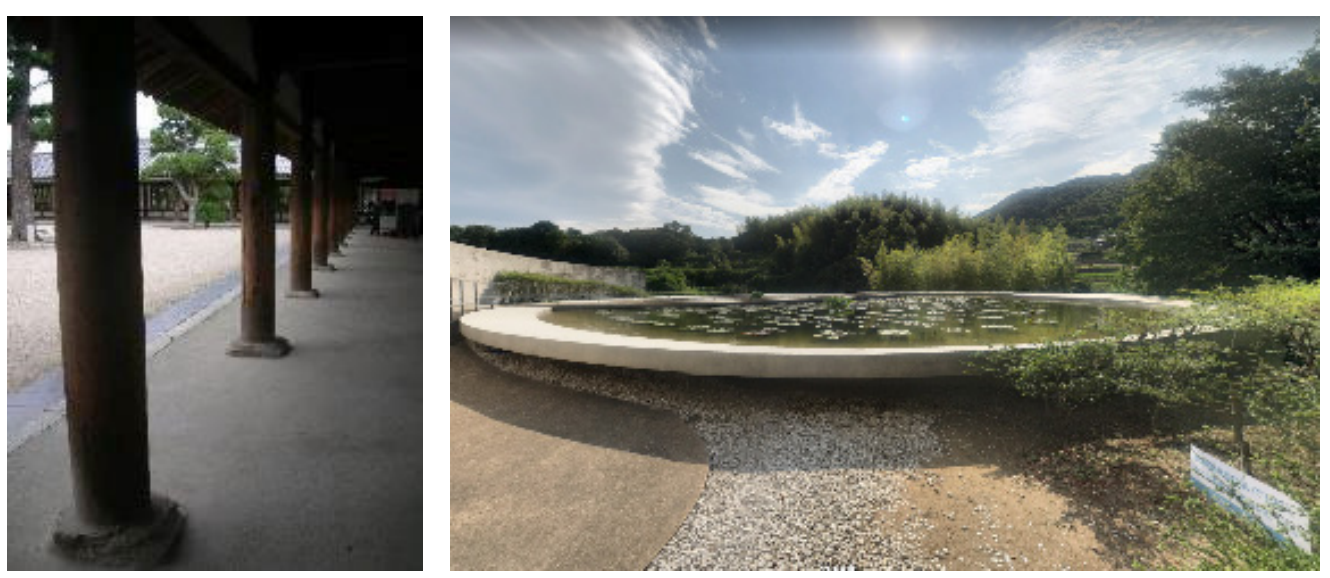

Figura 11. A la izquierda se presenta el corredor con gravilla del complejo Horyu ji en Kioto, Japón ${ }^{28}$. A la derecha se muestra el acceso con gravilla al estanque de agua del Templo del Agua en Awaji, Japón, obra de Tadao Ando en el $2004^{29}$

Respecto al gran espejo de agua con las flores de loto, las escrituras narran que Buda contempló entonces el mundo y en una visión toda la humanidad apareció como un estanque lleno de flores de loto, y por medio de esta visión es que se comprende la metáfora de las fases del desarrollo del ser humano y se asocia con el símbolo de revelación espiritual (ver figura 12). Como si el espejo de agua pretendiera atrapar en su reflejo la naturaleza que lo rodea, este templo que nace y sucumbe en el agua, con su forma ovalada, simboliza el agua donde se refleja la luna, es decir, donde confluyen todas las enseñanzas y la comprensión de sí y el mundo. Es un espacio donde la luz surge como una guía que nos conduce a muchas experiencias sensoriales al introducirnos al templo a través de la escalinata. 
Manifestaciones del pensamiento japonés...

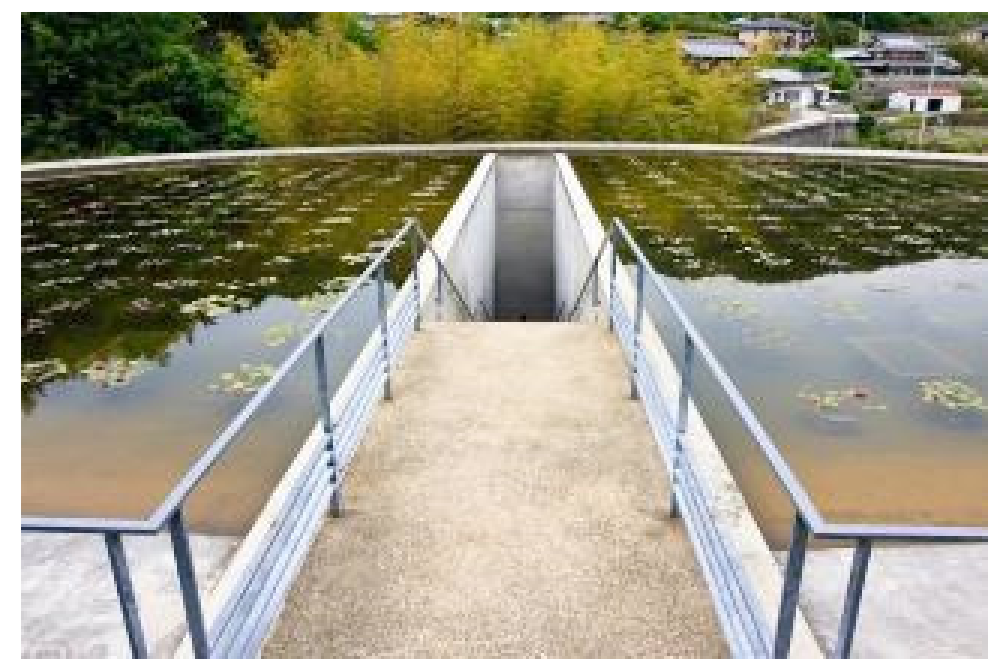

Figura 12. Estanque de flores de loto en el Templo del agua.

Ando hace una arquitectura que tiene ese tipo de sensibilidad sutil que solo un japonés podría hacer porque el pensamiento japonés es capaz de tratar el agua y la luz como un ser vivo sin llegar al panteísmo o animismo como él lo expresó (Auping, 2003, p. 25). En su arquitectura, esos elementos juntos pueden hacernos sentir que estamos vivos y llegar a comprender nuestra condición humana. 


\section{Conclusiones}

Tadao Ando, aislado de los arquitectos occidentales, así como de los japoneses, refleja su propio pensamiento en sus obras. Él tiene claramente fijada su posición: evita el formalismo y los estilos expresionistas mientras combina influencias de la tradición y la sensibilidad japonesas con aspectos más modernos, integrando conceptos espaciales orientales y occidentales.

En su arquitectura, la naturaleza es el medio que ayuda a lograr su objetivo de estimular el espíritu humano. Es la naturaleza arquitectónica, o naturaleza abstracta, la detonadora de emociones verdaderas que alcanzan su más alto valor. Es por ello que, en su obra, la naturaleza nunca es un elemento secundario, sino protagonista.

Tadao Ando conceptualiza la arquitectura como un pensamiento donde vincula su naturaleza espiritual y los valores humanos que se perciben en los símbolos que introducen y enaltecen su obra, que muestran la impronta de su origen. El arquitecto se ha aproximado a invaluables contribuciones para el discurso arquitectónico en términos de ideologías y de la práctica arquitectónica; para interpretar y valorar su obra, entonces, se debe partir desde el entendimiento de sus principios teóricos filosóficos.

Desde la perspectiva de Occidente, una de las más importantes características de los conceptos de Tadao Ando es el uso de la naturaleza, el vacío, el lugar, la luz, el aire y el espacio para comprender la condición humana y alcanzar la sabiduría. El espacio que crea y recrea, a través del uso de la geometría abstracta y dinámica, hace protagonista a la naturaleza misma.

En conjunto, la tradición japonesa, y más allá de la filosofía oriental, aparece como el fondo de la arquitectura de Ando; es una simbiosis de la lógica y el sentimiento, de la tecnología y la libertad artística de expresión, del Oriente y el Occidente. Su obra incluye religión, filosofía, estética, estilos de vida, costumbres, sensibilidad emocional, valores y sentido del orden. Aunque sus obras parecen ser construcciones estáticas, en ellas subyacen elementos que invitan a la reflexión y manifiestan una fuerte espiritualidad como resultado de su pensamiento. 


\section{Notas}

${ }^{1}$ Creado en 1979 y patrocinado por la fundación estadounidense Hyatt. Es el de mayor prestigio internacional y se le conoce comúnmente como el "Nobel de arquitectura". Recuperado de https://www.pritzkerprize.com/

2 Creado por la fundación danesa Carlsberg en 1991, reconoce la excelencia del diseño arquitectónico. Recuperado de http://www.carlsbergfondet.dk/en/ News/News-from-the-Foundation/News/The-Carlsberg-Foundations-researcherapartments-awarded-with-grand-Danish-architecture-prize

${ }^{3}$ Creado en 1989 por la familia imperial japonesa en memoria de su alteza imperial el príncipe Takamatsu en nombre de la Asociación de Arte de Japón. Recuperado de http://www.praemiumimperiale.org/en/

${ }^{4}$ Creado en 1985. Es el premio privado más importante de Japón, concedido por la Fundación Inamori a los mejores exponentes de cada área, pero, sobre todo, a los que han contribuido a la humanidad con su obra. Recuperado de https://www. kyotoprize.org/en/

\section{${ }^{5}$ Provincia.}

${ }^{6}$ Concepto cultural que significa el sentimiento y la percepción de las 4 estaciones y la profunda conciencia hacia las mismas.

7 Flor de cerezo de primavera. Recuperado de https://splurgefrugal.com/cherryblossoms-at-abq-biopark/ Vista de la Iglesia del Agua en verano. Recuperado de https://arquitecturaycristianismo.com/2012/09/23/la-iglesia-del-agua-de-tadaoando/ Vistas de la Iglesia del Agua en otoño e invierno. Rrecuperado de http:// moleskinearquitectonico.blogspot.com/2007/02/la-iglesia-sobre-el-agua.html

${ }^{8}$ El que profesa el shintō, 神道, religión nativa de Japón, que veneran a los Kami o espíritus de la naturaleza. 
9 El pabellón Alemán. Recuperado de https://3bonline.wordpress.com

${ }^{10}$ Recuperado de http://www.tadao-ando.com

${ }^{11}$ Arquitecto vienés. Estudia en la Escuela de Artes y Oficios Rama de Arquitectura en Reichenberg, Bohemia. Sus viviendas de Loos quedan definidas por tres conceptos arquitectónicos: Raumplan o Arquitectura de la Planta Espacial, Teoría del aterrazamiento y Teoría del Revestimiento. Recuperado de https://www. arquine.com/adolf-loos-espacios-privados/

${ }^{12}$ Casa Möller de Adolf Loos. Recuperado de http: //adolfloos.cz/en/villa-muller Casa Azuma de Tadao Ando. Recuperado de https://www.pinterest.com/decaubi/18tadao-ando-azuma-houserow-house-osaka-jap

13 Arquitecto nacionalizado estadounidense, quien nace en 1901 en Osel, Estonia. Estudia en la Universidad de Pensilvania, Filadelfia. Muere en 1974 en Nueva York. Recuperado de http://www.louiskahn.es/Biografia.html

${ }^{14}$ Arquitecto suizo con el nombre de Charles Edouard Jeanneret-Gris. Se trasladó a París donde adoptó el seudónimo Le Corbusier. En 1900 comenzó su aprendizaje como grabador y cincelador en la Escuela de Arte de La Chaux-de-Fonds, Suiza.

${ }^{15}$ Marco Vitruvio Polión (80-70 a. C.-15 a. C.) fue un arquitecto, escritor, ingeniero y tratadista romano del siglo I a. C.

${ }^{16}$ La palabra Shinto procede del chino Shintao 神道 que significa “camino de los dioses". Aunque se designa como religión, es necesario aclarar que la palabra religión no existía en japonés, sino que fue nombrada de esta manera para expresarse ante el mundooccidental.Dehecho, la palabra Shuukyo 宗教, queesunequivalenteareligión, etimológicamente significa Kyou 教 de enseñanza y Shuu 宗 desecta, de esta manera, el shinto no es considerado por los japoneses como una secta, pero sí el budismo. 
Manifestaciones del pensamiento japonés...

${ }^{17}$ Musubi constituye el Sangen que son los tres fundamentos u orígenes o, bien, elementos; el Iku musubi que es el Ki (fuerza o energía) y es la dimensión que fluye a través de la armonización, vaporización y fluidez. Simboliza la iniciativa y el reino animal y representa el constante nacimiento de la energía de la vida y la conciencia. El Taru Musubi que es la dimensión líquida, es la inhalación. Simboliza la unificación y el reino vegetal y representa la materialización y el cambio. Tamatsune musubi es la dimensión de lo sólido, es la forma y exhalación. Simboliza el reino mineral y representa la existencia física (Gleason, 1995, p. 93).

${ }^{18}$ Filósofo japonés de la Escuela de Kioto y discípulo de Kitarō Nishida (19001990). En 1924 Nishitani recibió un Ph.D. de la Universidad de Kyoto por su disertación Das Ideale und das Reale bei Schelling und Bergson. Estudió con Martin Heidegger en Friburgo de 1937-1939 (Heisig, 2001, p. 183).

${ }^{19}$ Claraboya o abertura de forma circular u oval.

${ }^{20}$ Templo de planta circular erigido en Roma por Adriano entre los años 118 y 125 d. C.

21 Óculo del Panteón de Agripa (118 y 125 d. C.). Recuperado de https://www. jotdown.es Óvalo de la Casa Museo Benesse (1992). Recuperado de http:// benesseartsite.jp/en/art/benessehouse-museum.html.

${ }^{22}$ Sumo Sacerdote del Gran Santuario Tsubaki en la Prefectura de Mie en Japón, escritor de numerosos libros shintoistas como Kami no michi o El camino de los Kami y Kodama el camino del Shinto.

${ }^{23}$ Recuperado de http://www.andotadao.org/chlight6.htm

${ }^{24}$ Recuperado de https://www.google.com/maps/place/Chapel+on+the+water/

25 Vista del interior al exterior de la Iglesia del agua. Recuperado de www. tadaoando.com Flor de loto sobre el agua. Recuperado de https://www.pinterest. es/pin/ Vista del Santuario de Itsukushima (foto propia). 
${ }^{26}$ Recuperado de https://www.pinterest.com.mx

${ }^{27}$ Foto propia.

${ }^{28}$ Foto propia.

${ }^{29}$ Templo del Agua en Awaji, Japón. Recuperado de https://www.pinterest.com. $\mathrm{mx}$

30 Templo del agua. Recuperado de https://www.pinterest.com

\section{Referencias}

Ando, T. (1993). Complete works. London, Inglaterra: Phaidon Press.

Auping, M. (2003). Tadao Ando. Conversaciones con Michael Auping.

Barcelona, España: Gustavo Gili.

Boyd, J. W. (2005). Japanese shinto: An interpretation of a priestly perspective. New York: Philosophy East \& West 55.

Bukkyo Dendo Kyokai. (1984). Teaching of Buddha. Tokio, Japón: Bukkyo Dendo Kyokai.

Dogen, E. (2009). El gran Shobogenzo (Trad. J. Ubalde Merino). Buenos Aires, Argentina: Dunken.

Dogen, Z. (2008). First Dogen book: Selected essays from Dogen Zenji's Shobogenzo (Trad. T. B. Myers). Colombia Británica, Canadá: CreateSpace Independent Publishing Platform.

Frampton, K. (1995). Thoughts on Tadao Ando. Recuperado de https://www. pritzkerprize.com/sites/default/files/inline-files/1995_essay.pdf 
Manifestaciones del pensamiento japonés...

Gleason, W. (1995). The spiritual foundations of aikido. Estados Unidos: Inner Traditions Bear and Company

Havens, N. (1998). Inmanet legitimation: reflections on the "Kami" concept. Recuperado de https://www2.kokugakuin.ac.jp/ijcc/wp/cpjr/kami/havens. html

Heisig, J. (2001). Philosophers of nothingness. Honolulu, Hawái: University of Hawaii Press.

Molinari, L. (2003). Tadao Ando: museums. Roma, Italia: Skira.

Pham, T. (1998). Abstraction and transcendence: nature, shintai, and geometry in architecture of Tadao Ando. Recuperado de http://dissertation.com/books/158112029X

Surya, L. (2008). El despertar del Buda interior (Trad. M. Velázquez). Madrid, España: EDAF.

Watts, A. W. (2003). El camino del zen. Barcelona, España: EDHASA. 